\title{
Transmission dynamics of intramammary infections with coagulase-negative staphylococci
}

\author{
O. Reksen, ${ }^{* 1}$ Y. T. Gröhn, † J. W. Barlow,‡ and Y. H. Schukken† \\ *Norwegian School of Veterinary Science, Department of Production Animal Clinical Sciences, PO Box 8146, N-0033 Oslo, Norway \\ †Department of Population Medicine and Diagnostic Sciences, Cornell University, Ithaca, NY 14850 \\ $\ddagger$ Department of Animal Science, University of Vermont, Burlington 05405
}

\section{ABSTRACT}

A field trial was conducted on 2 US dairy herds to evaluate the transmission dynamics of coagulase-negative staphylococci (CNS) during the lactation period. Quarter milk cultures positive for CNS were classified as intramammary infection (IMI) or incidental isolation (transient colonization). The average proportion of quarters with CNS IMI was 0.114 in farm 1 and 0.09 in farm 2, and corresponding estimates for quarters with transient colonization of CNS were 0.122 and 0.088 throughout the 13-mo study period. Transmission parameters were obtained both for IMI caused by CNS and for CNS-positive quarters classified as the combination of transient colonization and IMI. Transmission between cows and between quarters in the same cow was assessed. The transmission parameters $(\beta)$ for IMI caused by CNS were 0.0066 (farm 1) and 0.0111 (farm 2 ). Corresponding estimates of $\beta$ when IMI and transient colonization of CNS were assessed jointly were 0.0256 (farm 1) and 0.0253 (farm 2). On farm 1, risk of transmission for CNS IMI between quarters in the same cow was 2 times greater than that between quarters from cow to cow. Transmission of CNS was considered contagious in one farm but no distinction between contagious and environmental transmission could be made in the other. We hypothesize that between-farm variation may be related to diversity between prevailing CNS species or by differences in management. In the current study, estimates of the basic reproduction number $\left(\mathrm{R}_{0}\right)$ at the farm level for CNS IMI were 0.59 and 0.84 in farms 1 and 2, respectively. This shows that the transmission of CNS from IMI during the lactation period would to be too low to maintain the observed herd prevalence of CNS IMI. The $\mathrm{R}_{0}$ values for the combination of transient colonization and IMI by CNS were 1.13 and 1.17 in farms 1 and 2, respectively. This

Received July 1, 2011.

Accepted March 21, 2012.

${ }^{1}$ Corresponding author: Olav.Reksen@nvh.no indicates potential for sustained endemic infection of CNS throughout lactation. However, prevailing CNS species may also differ between transient colonization and IMI. Therefore, not only CNS originating from IMI or incidental isolation events, but also CNS IMI occurring from the period outside the lactation pen are essential for maintenance of the observed herd prevalence of CNS IMI throughout lactation in this study. The effect of IMI originating outside the lactation pen was verified in simulations with reduced entry of infectious quarters to the lactation pens. Measures against CNS IMI would probably increase in efficiency if prevention of infection during the dry period and early lactation were further emphasized in herd health programs.

Key words: intramammary infection, cow, coagulasenegative staphylococci, mathematical modeling

\section{INTRODUCTION}

Although long regarded as minor pathogens (Djabri et al., 2002; Pyörälä and Taponen, 2009; Taponen and Pyörälä, 2009), CNS are receiving increased attention among mastitis researchers (Schukken et al., 2009; Taponen and Pyörälä, 2009; Thorberg et al., 2009). The CNS bacteria are frequently isolated from cases of subclinical mastitis and mild clinical cases of IMI (Dingwell et al., 2004; Pitkala et al., 2004; Taponen et al., 2006; Østerås et al., 2006), and a positive bacteriological diagnosis of CNS is likely to be related to moderately elevated SCC at the cow and herd level (Djabri et al., 2002; Reksen et al., 2008; Schukken et al., 2009). Furthermore, the CNS is a heterogeneous group of species with differing predilection and pathogenicity (Aarestrup et al., 1999; De Vliegher et al., 2003; Taponen et al., 2007; Supré et al., 2011), characteristics that may challenge the choice of control strategy (Davidson et al., 1992; Thorberg et al., 2009). Even though culling rarely seems to be the outcome of a positive diagnosis for subclinical CNS mastitis at cow level (Reksen et al., 2006), herd problems related to increased bulk milk SCC have been reported (Schukken et al., 2009; Thorberg et al., 2009). Particularly in herds striving for a 
low bulk milk SCC, CNS IMI may pose a significant challenge to producers' milk quality goals.

The CNS species isolated from the teat skin, teat apex, and teat canal are generally different from the CNS species isolated from milk (De Vliegher et al., 2003; Taponen and Pyörälä, 2009). Staphylococcus chromogenes, Staphylococcus simulans, and Staphylococcus epidermidis are the most frequently isolated CNS from milk samples across several studies (Matthews et al., 1992; Todhunter et al., 1993; Aarestrup and Jensen, 1997; Waage et al., 1999; Taponen et al., 2006). Recent studies have also shown that persistent IMI are common in quarters infected with these CNS species (Taponen et al., 2007; Thorberg et al., 2009; Supré et al., 2011).

Later stages of lactation and the periods around drying off and calving have been identified as risk periods for CNS IMI (Davidson et al., 1992; Todhunter et al., 1993; Taponen et al., 2007), but the epidemiology of CNS deserves further attention (Pyörälä and Taponen, 2009; Thorberg et al., 2009). Deterministic state-transition models have previously been used to describe mammary pathogen transmission dynamics. Model characteristics such as transmission parameter $(\boldsymbol{\beta})$, spontaneous cure rate $(\boldsymbol{\alpha})$, basic reproduction number $\left(\mathbf{R}_{\mathbf{0}}\right)$, and effective reproduction number $\left(\mathbf{R}_{\mathrm{t}}\right)$ were estimated from field data for Staphylococcus aureus (Zadoks et al., 2002; Barlow et al., 2009) and Escherichia coli (White et al., 2010). The $\mathrm{R}_{0}$ is the number of secondary cases that arises per infectious individual in a fully susceptible population, whereas $R_{t}$ is the effective number of cases arising per infectious individual throughout an epidemic or endemic infection (Keeling and Rohani, 2007). Typically, an $\mathrm{R}_{0}>1$ determines whether a disease outbreak is likely to occur in a fully susceptible population, and values of $R_{t}$ are likely to be less than values of $R_{0}$. The difference between $R_{t}$ and $\mathrm{R}_{0}$ is directly related to the proportion of susceptible individuals that decreases throughout the lifetime of an epidemic or endemic infection (Keeling and Rohani, 2007). It has been shown, however, that $R_{t}$ may exceed $\mathrm{R}_{0}$ in cases where susceptibility or infectiousness increases during the establishment of an infectious agent in a population (Barlow et al., 2009). In such cases, the infection may be sustained in the population although $\mathrm{R}_{0}$ may be too small $(<1)$ to initiate a disease outbreak in the first place. In such situations, the eradication effort is no longer determined by $\mathrm{R}_{0}$ alone (Safan et al., 2006). A relevant question in our study is whether a CNS IMI in neighboring quarter(s) may increase susceptibility in noninfected quarters of the same cow and thereby contribute to maintenance of an endemic infection.

In the current investigation, we applied a deterministic susceptible-infectious-susceptible (SIS) model to study the transmission potential of CNS IMI in 2 farms, where IMI was differentiated from incidental isolation events by predefined threshold values for CNS counts $(\mathrm{cfu} / \mathrm{mL})$ and repeated occurrences of CNS in monthly milk cultures (Zadoks et al., 2002). Specifically, the objectives of our study were to (1) quantify the transmission parameters for CNS IMI, (2) quantify the transmission parameters for the entire population of CNS-positive quarters comprising IMI and incidental isolation events, (3) quantify the relative influence of quarter-to-quarter transmission of CNS IMI within the same cow, (4) quantify the relative risk (RR) of a second CNS IMI event in a quarter previously diagnosed with CNS IMI, and (5) develop a mathematical model that allows simulation of CNS IMI in scenarios with different control strategies and infection pressure.

\section{MATERIALS AND METHODS}

\section{Field Study}

Description of the Study Site. The field study was conducted for a period of 13 mo during 2003 and 2004 in 2 commercial dairy herds (one each in New York and Vermont) milking Holstein dairy cows. Criteria for herd participation included (1) reliable individual cattle identification; (2) mastitis control practices including pre- and postmilking teat disinfection and blanket use of dry-cow therapy; (3) the farmers were willing to keep written records on all cows, including dates of calving, entries and exits from lactating pen, clinical disease, treatment, and culling; and (4) cows receiving medical treatment for mastitis were housed in a separate pen. Cows received medical treatment for mastitis for 2 reasons: (1) the farmer observed clinical mastitis and (2) in 1 of the 2 pens per farm, cows were treated for subclinical mastitis caused by streptococci and Staph. aureus.

Two groups of approximately 100 lactating cows on each farm were studied. All pens contained animals from first to eighth parity in all stages of lactation. The farms raised their own replacement stock. Entry and exit of individuals into the lactation pens followed normal management routines. Cows normally entered the lactation pen about 1 wk after calving. Dates of all entries and exits were recorded for each cow. Cows on each farm were milked 3 times per day in a milking parlor. Pens of cows within each herd were milked in the following order at each milking session: fresh cow group, pens enrolled in the study, additional pens not enrolled in the study. The milking system was washed and sanitized 3 times daily after milking the entire herd.

Milk Sampling and Bacteriologic Analysis. Individual quarter milk samples were collected for 
microbiological analysis from all cows at the start of the study, at monthly intervals for the duration of the study, and at the end of the study. Quarter milk samples were also collected from all cows within $3 \mathrm{~d}$ following parturition and when cows were added to or removed from the lactation pens. Monthly sample collection was conducted by trained field technicians, and farm personnel were trained to collect all additional samples following established aseptic methods (Hogan et al., 1999). Samples collected by farm personnel were immediately stored frozen at $-20^{\circ} \mathrm{C}$ and transported frozen to the microbiology laboratory at 2-wk intervals. Monthly samples were held on ice immediately following collection and during transport to the laboratory, and were stored frozen at $-20^{\circ} \mathrm{C}$ for 24 to $72 \mathrm{~h}$. All samples were thawed overnight under refrigeration and aerobic bacteriologic culture and interpretation of results were performed according to established guidelines (Hogan et al., 1999). Samples with $>3$ morphologically distinct colony types were considered contaminated and eliminated from analysis.

IMI and Incidental Isolation Events of CNS. Sequential quarter-level bacteriologic culture was used to define IMI status as previously described by Zadoks et al. (2002). Individual CNS positive quarters were categorized as IMI when adhering to at least one of the following criteria: 1) $\geq 1,000 \mathrm{cfu}$ of $\mathrm{CNS} / \mathrm{mL}$ from a single sample, 2) $\geq 500 \mathrm{cfu}$ of CNS/mL from 2 out of 3 consecutive samples, 3 ) $\geq 100 \mathrm{cfu}$ of CNS $/ \mathrm{mL}$ from 3 of 3 consecutive samples, or 4) $\geq 100 \mathrm{cfu}$ of $\mathrm{CNS} / \mathrm{mL}$ from a clinical mastitis case. Clinical IMI was defined as abnormal milk with or without accompanying swelling or pain in the udder and systemic signs such as elevated rectal temperature, lethargy, or anorexia (International Dairy Federation, 1987; Harmon, 1994). Samples with CNS that did not meet the above criteria were defined as incidental isolation events (transient colonization).

Duration of infection was calculated based on the mid-point estimation method previously described by Zadoks et al. (2002), where the start of the IMI was defined as the middle of the time interval between a negative culture and the first positive culture event, and the end of the IMI was defined as the middle of the time interval between the last positive culture and the first negative culture event for a quarter defined as cured. Quarter-days infected with CNS in the lactation pens were calculated based on (1) recorded date of entry for infected quarters, (2) dates of new infections, (3) dates of cure, or (4) exit from the lactation pens for noncured quarters. A quarter was considered cured from IMI when found negative for CNS in 2 consecutive monthly milk samples after a positive diagnosis for CNS IMI. Quarter-days susceptible (i.e., days at risk for a new CNS event among uninfected quarters) were calculated based on recorded dates of cow entry and exit from the lactation pens accounting for the date of changes in quarter infection status during each interval.

Naive susceptible quarters (S) were defined as quarters in a cow where none of the lactating quarters was harboring a CNS IMI. A quarter was categorized as S also when positive for other microorganisms than CNS. However, if a quarter received antibiotic treatment for clinical or subclinical mastitis, the cow (i.e., all 4 quarters) was removed from the susceptible group for the period the cow was housed in the treatment pen. Susceptible quarters in a cow where one or more of the neighboring quarters $\left(\mathbf{S}_{\mathrm{w}}\right)$ were found positive for CNS IMI were identified for the assessment of within-cow transmission of CNS from already existing CNS IMI positive quarters. Quarters that were diagnosed positive for CNS IMI were defined as infectious (I). The infectious compartment included new CNS IMI events that emerged in the lactation pens and preexisting CNS IMI at the time the current quarter entered the lactation pen.

\section{Estimation of Transmission Parameters}

Statistical analyses were conducted using SAS version 9.1 (SAS Institute Inc., Cary, NC). Transmission parameters $\beta$ and cure rates $\alpha$ were calculated using the generalized linear model approach (PROC GENMOD). Evidence of overdispersion was evaluated, and models were subsequently adjusted using an overdispersion parameter estimated from the ratio of the Pearson $\chi^{2}$ estimate divided by the remaining degrees of freedom (Pscale option).

CNS Transmission Parameter Estimates Adjusted for Increased Risk of Transmission within Cow. Transmission parameters $(\beta)$ were estimated in farm-specific linearized models with number of new CNS IMI events in each monthly interval $\left(\mathrm{I}_{\mathrm{M}}\right)$ as the outcome; $\mathrm{S}=$ quarter-days in a naive susceptible udder; $\mathrm{S}_{\mathrm{w}}=$ quarter-days in susceptible udders where one or more other quarters were CNS IMI positive; I = quarter-days infected, $\mathrm{N}=$ total quarter-days in each interval, and $\beta^{*}$ is the intercept in the equation

$$
\ln \left(I_{M}\right)=\beta^{*}+\ln \frac{\left(S+S_{w}\right) I}{N} .
$$

A log link, assumption of a negative binomial distribution, and offset (Zadoks et al., 2002) was used:

$$
\ln \frac{\left(S+S_{w}\right) I}{N} .
$$


To evaluate the effect of an existing CNS IMI on transmission dynamics, model fit was assessed by comparing the 2log-likelihood ratio between a model with the complete offset term included and a model without the term I/N included in the offset. The chi-squared statistic was used for comparison. The effect of an existing CNS IMI on the transmission to an uninfected quarter in the same cow was assessed by including preexisting infection $\left(\boldsymbol{\sigma}^{*}\right)$ in the same udder as a binary variable in the farm-specific generalized linear models:

$$
\ln \left(I_{M}\right)=\beta^{*}+\sigma^{*}+\ln \frac{\left(S+S_{w}\right) I}{N},
$$

where $\beta$ (intercept) $=\mathrm{e}^{\beta^{*}}=$ the transmission parameter, and $\mathrm{e}^{\sigma^{*}}$ is the modifier of the transmission parameter to estimate the within-cow quarter-to-quarter transmission. The estimations were repeated for the assessment of $(\beta)$ with $\mathrm{I}_{\mathrm{M}}=$ any new event of CNS positive diagnoses (transient colonization or IMI), and I = number of CNS-positive quarter days. In this model, $\mathrm{S}$ and $\mathrm{S}_{\mathrm{w}}$ referred to CNS-negative quarters.

Cure Rate. Cure rate $(\alpha)$ was estimated with number of cured quarters from CNS IMI events in each monthly interval $\left(\mathrm{C}_{\mathrm{M}}\right)$ as the outcome. A log link, assumption of a negative binomial distribution, and offset $\ln (\mathrm{I})$ (Zadoks et al., 2002) was used in the equation:

$$
\ln \left(\mathrm{C}_{\mathrm{M}}\right)=\alpha+\ln (\mathrm{I}),
$$

where $\mathrm{C}_{\mathrm{M}}=$ cured CNS IMI events in each monthly interval, I = quarter-days infected in each monthly interval, $\alpha$ is the intercept, and the cure rate $\alpha$ is expressed as $\mathrm{e}^{\alpha}$. The estimation was repeated for the assessment of $(\alpha)$ with $\mathrm{I}_{\mathrm{M}}=$ any new event of CNS positive diagnoses (transient colonization or IMI), and I = number of CNS positive quarter days.

Daily Rate of Entry and Exit of Quarters from the Lactation Pens. Quarters entered the lactation pens according to common management procedures (e.g., after calving, treatment, purchase). In a stable population, the sum of these rates $(\mu)$ is equivalent to the rate of quarters that exited the lactation pens (e.g., culling, sale, dry off, treatment). The proportion of cows entering the $\mathrm{S}, \mathrm{S}_{\mathrm{w}}$, or I compartments throughout the simulation were estimated from farmers' records of animal movement and the current microbiological status of each quarter. Initial values for the proportion of quarters in $\mathrm{S}, \mathrm{S}_{\mathrm{w}}$, and I were calculated based on the prevalence during first month of study.

Risk of a Second CNS IMI in Quarters Previously Diagnosed with CNS IMI. For CNS IMI, the possible influence of a previous CNS event in the same quarter was also assessed using the equation

$$
\ln \left(I_{M}\right)=\beta^{*}+\gamma^{*}+\ln \frac{\left(S+S_{w}\right) I}{N},
$$

where $I_{M}$ equals new CNS IMI events per unit of time, $\beta$ (intercept) $=\mathrm{e}^{\beta^{*}}=$ the transmission parameter, and $\mathrm{e}^{\gamma^{*}}$ is the modifier of infection number (1 vs. 2) during the current lactation.

\section{Simulations}

Model Definition. A model used for simulation of CNS IMI at the quarter level (Figure 1) was developed using the ModelMaker 4 software (ModelKinetix, Wallingford, UK). A classical SIS model was used (Keeling and Rohani, 2007), and the unit of study was lactating udder quarter. Although SIS models normally assume random mixing between all individuals (= quarters) in a population, the current model was modified to assess the influence of quarter-to-quarter infection within the same cow (Zadoks et al., 2002; White et al., 2006; Barlow et al., 2009). The model (Figure 1) has 3 compartments: (1) $\mathrm{S}=$ naive susceptible quarters, (2) $\mathrm{S}_{\mathrm{w}}$ = susceptible quarters in a cow harboring preexisting IMI, and (3) I = quarters affected with an IMI caused by CNS.

Initial model parameters were calculated from the data obtained from farms 1 and 2. The model was defined by a set of 3 ordinary differential equations describing the change in proportion of quarters within each compartment over time:

$$
\begin{gathered}
\frac{d S}{d t}=(\theta S N \mu)+(\alpha I P)+\left(\alpha S_{w}\right)-(4 \beta S I)-(\mu \mathrm{S}), \\
\frac{d S_{w}}{d t}=(\theta S w N \mu)+(3 \beta S I)+[\alpha I(1-P)] \\
-\left(\sigma \beta S_{w} I\right)-\left(\alpha S_{w}\right)-\left(\mu S_{w}\right), \\
\frac{d I}{d t}=(\theta I N \mu)+(\beta S I)+(\sigma \beta S w I)-[\alpha I(1-P)] \\
-(\alpha I P)-(\mu I),
\end{gathered}
$$

where $\mathrm{S}=$ proportion of susceptible quarters in cows with no CNS IMI; $\mathrm{S}_{\mathrm{w}}=$ proportion of susceptible quarters in cows with CNS IMI; I = proportion of infectious quarters; $\beta=$ transmission parameter - the probability per unit of time that an infectious quarter will infect an uninfected quarter (Keeling and Rohani, 2007); $\alpha=$ daily rate of cured quarters; $\mathrm{N}=$ number of quarters 


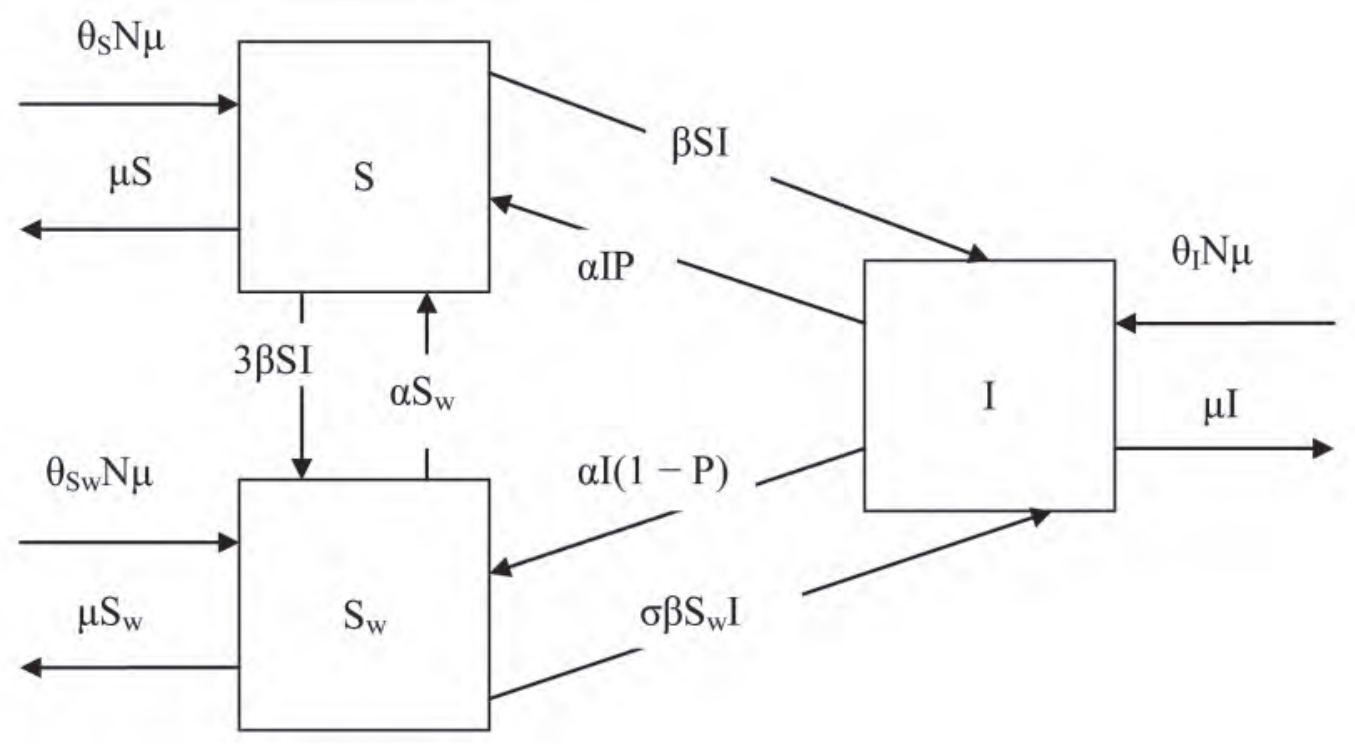

Figure 1. Flow diagram of the state transmission model of IMI from CNS in a population of lactating quarters. The boxes represent the state variables: $\mathrm{S}=$ naive susceptible quarter, $\mathrm{S}_{\mathrm{w}}=$ susceptible quarter in a cow with a simultaneous infection in one or more other quarter(s), and $\mathrm{I}=$ quarter affected with an IMI by CNS. The arrows represent the flow rate between the compartments: $\mathrm{S}$ to $\mathrm{I}=\beta$ SI, $\mathrm{S}$ to $\mathrm{S}_{\mathrm{w}}=3 \beta \mathrm{SI}$, $\mathrm{I}$ to $\mathrm{S}=\alpha \mathrm{IP}$, I to $\mathrm{S}_{\mathrm{w}}=\alpha \mathrm{I}(1-\mathrm{P}), \mathrm{S}_{\mathrm{w}}$ to $\mathrm{S}=\alpha \mathrm{S}_{\mathrm{w}}, \mathrm{S}_{\mathrm{w}}$ to $\mathrm{I}=\sigma \beta \mathrm{S}_{\mathrm{w}} \mathrm{I}$. Entries of quarters from the fresh pen to the different compartments in the lactation pen are determined by the proportions $\theta_{\mathrm{S}}, \theta_{\mathrm{SW}}$, and $\theta_{\mathrm{I}}\left(\theta_{\mathrm{S}}+\theta_{\mathrm{SW}}+\theta_{\mathrm{I}}=1\right)$ multiplied by $\mu \times \mathrm{N}$, where $\mu=$ the daily rate of entry and exit of quarters to and from the lactation pens, and $\mathrm{N}=$ number of quarters in the study at any given time. Exit is determined by $\mathrm{S}$, $\mathrm{S}_{\mathrm{w}}$, and $\mathrm{I}$ multiplied by $\mu$ respectively; $n=$ number of quarters in the study at any given time $\left(\mathrm{I}+\mathrm{S}+\mathrm{S}_{\mathrm{w}}=1\right)$. $\mathrm{P}=$ function for the estimation of proportion of cows with only one quarter infected, approximated by $\mathrm{P}=\mathrm{S}_{\mathrm{w}} / 3 \mathrm{I} ; \beta \mathrm{SI}=$ new infections per day; $3 \beta \mathrm{SI}$ : for each infected quarter in a naive susceptible cow $(\mathrm{S})$, the number of susceptible quarters that change status from $\mathrm{S}$ to $\mathrm{S}_{\mathrm{w}}$ is approximated by the factor 3 . $\alpha \mathrm{IP}$ and $\alpha \mathrm{I}(1-\mathrm{P})$ : flow of cured quarters from I to $\mathrm{S}$ or $\mathrm{S}_{\mathrm{w}}$ is approximated by the proportion of cows with only one infected quarter $\left(\mathrm{S}_{\mathrm{w}} / 3 \mathrm{I}\right)$, cure rate $(\alpha)$, and number of infectious quarters (I); $\sigma=$ adjustment for increased risk of transmission between quarters in the same cow; $\mu=$ overall daily rate of new quarters entering the lactation pen.

in the study at any given time $\left(\mathrm{I}+\mathrm{S}+\mathrm{S}_{\mathrm{w}}=1\right) ; \mathrm{P}=$ function for the estimation of proportion of cows with only one quarter infected, approximated by $\mathrm{P}=\mathrm{S}_{\mathrm{w}} / 3 \mathrm{I}$; and $\sigma=$ increased risk of within-cow transmission for an $\mathrm{S}_{\mathrm{w}}$ quarter. The number of new CNS IMI from $\mathrm{S}$ was estimated as $\beta$ SI; the number of new CNS IMI from $S_{w}$ was estimated as $\sigma \beta S_{w} I$; the number of cured quarters from I to $\mathrm{S}$ was estimated as $\alpha \mathrm{IP}$; and the number of cured quarters from I to $\mathrm{S}_{\mathrm{w}}$ was estimated as $\alpha \mathrm{I}(1-\mathrm{P})$. The number of susceptible quarters from $\mathrm{S}$ to $\mathrm{S}_{\mathrm{w}}=$ $3 \beta \mathrm{SI}$; and the number of susceptible quarters from $\mathrm{S}_{\mathrm{w}}$ to $S=\alpha S_{w}$. The daily rate of entry and exit of quarters to and from the lactation pens $=\mu$; and the proportion of $\mu$ entering $\mathrm{S}=\theta_{\mathrm{S}}=1-\left(\theta_{\mathrm{I}}+\theta_{\mathrm{Sw}}\right)$; the proportion of $\mu$ entering $S_{\mathrm{w}}=\theta_{\mathrm{Sw}}=1-\left(\theta_{\mathrm{I}}+\theta_{\mathrm{S}}\right)$; and the proportion of $\mu$ entering $\mathrm{I}=\theta_{\mathrm{I}}=1-\left(\theta_{\mathrm{S}}+\theta_{\mathrm{Sw}}\right)$.

We used the key assumption for stable populations that quarters exited the 2 lactation pens at each farm at the same rate as new quarters entered the pens such that the population size remained constant throughout the study period: $\mu\left(S+S_{w}+I\right)=\left(\theta_{S}+\theta_{S w}+\theta_{I}\right) \mu N$.

Basic and Effective Reproduction Number. Transmission dynamics were further evaluated by the means of $\mathrm{R}_{0}$ and $\mathrm{R}_{\mathrm{t}}$ (Zadoks et al., 2002; Keeling and Rohani, 2007). The following definitions were used:

$$
\begin{gathered}
R_{0}=\frac{\beta}{\mu+\alpha}, \\
R_{t}=\frac{\frac{\beta S}{N}+\frac{\sigma \beta S w}{N}}{\mu+\alpha}=\frac{\beta\left(S+\sigma S_{w}\right)}{N(\mu+\alpha)} .
\end{gathered}
$$

The effective reproductive rate $\left(R_{t}\right)$ estimates the average number of secondary cases per infectious case in a population made up of both susceptible and nonsusceptible hosts. Therefore, the proportion of susceptible $\left(\mathrm{S}+\mathrm{S}_{\mathrm{w}}\right)$ relative to the total number of quarters $(\mathrm{N})$ is included in the assessment of $\mathrm{R}_{\mathrm{t}}$.

Transmission Scenarios of CNS IMI. The SIS models were used for the simulations in the current study. All simulations were conducted for a 13-mo period (400 d). Simulations were run separately for each farm to assess 3 scenarios. First, separate farm-specific models were run for the assessment of $S, S_{w}, I$, and $R_{t}$ 
for IMI by CNS. The models were corrected for transmission between quarters within the same cow. Second, preventive measures outside the main lactation period (dryoff, calving) are expected to decrease the entry of infected quarters into the lactation pens. To investigate this effect, simulations for CNS IMI were run where the entry of already infected quarters into the lactation pen was reduced to half the true daily rate in the first scenario and to zero in the second setting. Third, transmission parameters might increase due to changes in management. To simulate this scenario, simulations were run for CNS IMI after increasing the transmission parameter by $50 \%$ in each farm.

\section{RESULTS}

\section{IMI and Transient Colonization of CNS}

Monthly average milk production and cow composite SCC throughout the investigation period were $32 \mathrm{~kg}$ and 404,000 cells $/ \mathrm{mL}$ in farm 1 . The corresponding estimates for farm 2 were $41.9 \mathrm{~kg}$ and 292,000 cells $/ \mathrm{mL}$. The average herd size of farm 1 was 320 lactating cows, and that of farm 2 was 350 cows. In farm 1, 11,588 milk samples were collected during the 13-mo study period. Coagulase-negative staphylococci were detected in 2,734 samples (23.5\%), of which 1,316 qualified as IMI $(11.4 \%)$ and $1,418(12.2 \%)$ as transient colonization, according to the current definition. In farm 1, 132 new CNS IMI in 125 cows originated in the lactation pens throughout the study. Only 4 of the cases of CNS IMI were identified by the presence of clinical signs.

In farm 2, 10,271 milk samples were collected during the 13 mo of study. Coagulase-negative staphylococci were detected in 1,919 samples (18.7\%), of which 1,013 $(9.9 \%)$ qualified as IMI and $906(8.9 \%)$ as transient colonization, according to the definition. In farm 2, 159 new CNS IMI in 155 cows were diagnosed as having originated in the lactation pens throughout the study. None of the cases of CNS IMI were accompanied by clinical signs. Prevalence of CNS-positive diagnoses by lactation month from farms 1 and 2 are shown in Figure 2. The prevalence of CNS was relatively low during the first month in milk in both farms. Although an increase in CNS prevalence toward the end of lactation was apparent in farm 1, this was not seen in farm 2 .

\section{Estimation of Transmission Parameters}

Estimates for CNS Transmission Parameters and Cure Rates. Parameter estimates, confidence intervals, and $P$-values for the transmission parameter $(\beta)$ and cure rates $(\alpha)$ for CNS events as predicted from farm-specific generalized linear models based on the negative binomial distribution are shown in Table 1. Higher transmission parameters and cure rates were found for the combination of transient colonization and IMI by CNS compared with the assessments based solely on CNS IMI (Table 1). In farm 1, the transmission parameter and cure rate for the combination of transient colonization and IMI were 0.0256 and 0.0178 , whereas corresponding estimates for CNS IMI were 0.0066 and 0.0062 . Likewise, in farm 2, the transmission parameter and cure rate for the combination of transient colonization and IMI were 0.0253 and 0.0167 , whereas corresponding estimates for CNS IMI were 0.0111 and 0.0081 .

Transmission of CNS IMI from One Quarter to the Next in the Same Cow. In farm 1, RR of transmission of CNS IMI from one quarter to the next in the same cow was $1.99=\mathrm{e}^{0.6888}$ (95\% CI: $1.35-2.94$; $P<0.001)$. Assessment of model fit for $\beta$ showed a significant contribution of $\mathrm{I} / \mathrm{N}$ for model fit $\left(\chi^{2}, 1 \mathrm{df}\right.$ $=6,45)$, which demonstrates the effect of existing CNS IMI on transmission dynamics in this farm. In farm 2 , $\mathrm{RR}$ of within cow transmission of CNS IMI was 0.99 $=\mathrm{e}^{-0.0094}(95 \%$ CI: $0.74-1.43 ; P=0.45)$. Assessment of model fit for $\beta$ showed that exclusion of $\mathrm{I} / \mathrm{N}$ from the offset did not significantly change model fit, which indicate a limited effect of CNS IMI during lactation for transmission dynamics in this farm.
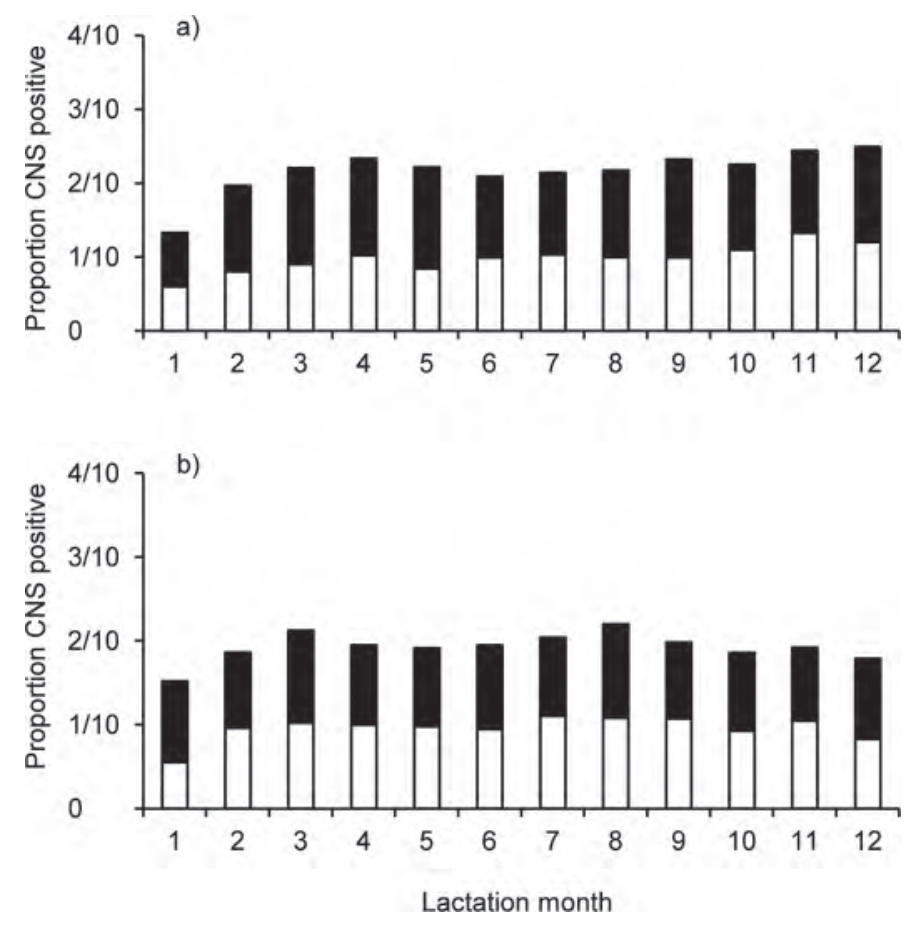

Figure 2. Positive diagnoses for CNS throughout lactation in farm 1 (a) and farm 2 (b). $\boldsymbol{\square}=$ transient colonization of CNS; $\square=$ IMI by CNS. The IMI status based on definitions of Zadoks et al. (2002). 
Table 1. Transmission parameter $(\beta)$ and cure rates $(\alpha)$, model parameters, and $95 \%$ CI estimated in farm-specific generalized linear models with the outcomes (a) combination of transient colonization and IMI by CNS and (b) IMI by CNS ${ }^{1}$

\begin{tabular}{|c|c|c|c|c|c|c|c|}
\hline$\frac{\text { Farm }}{1}$ & $\begin{array}{l}\text { CNS event } \\
\text { Colonization + IMI }\end{array}$ & $\beta\left(e^{\beta *}\right)$ & 0.0256 & $\beta^{*}$ & -3.65 & -3.82 & -3.47 \\
\hline \multirow{4}{*}{2} & IMI & $\beta\left(e^{\beta *}\right)$ & 0.0066 & $\beta^{*}$ & -5.02 & -5.24 & -4.81 \\
\hline & & $\alpha\left(e^{\alpha *}\right)$ & 0.0062 & $\alpha^{*}$ & -5.08 & -5.29 & -4.87 \\
\hline & Colonization + IMI & $\beta\left(e^{\beta *}\right)$ & 0.0253 & $\beta^{*}$ & -3.68 & -3.78 & -3.22 \\
\hline & & $\alpha\left(e^{\alpha *}\right)$ & 0.0167 & $\alpha^{*}$ & -4.09 & -4.28 & -3.90 \\
\hline
\end{tabular}

${ }^{1}$ IMI status based on definitions of Zadoks et al. (2002).

Daily Rate of Entry and Exit of Quarters from the Lactation Pens. In farm 1, for CNS IMI, the daily rate at which $\mathrm{S}$ quarters entered the herd was 0.00380 , the daily rate at which $\mathrm{S}_{\mathrm{w}}$ quarters entered the herd was 0.00069 , and the daily rate at which I quarters entered the herd was 0.00040. For the combined event of CNS IMI and transient colonization, the corresponding estimates for $\mathrm{S}, \mathrm{S}_{\mathrm{w}}$, and I were 0.00284, 0.00151, and 0.00088 , respectively.

In farm 2, for CNS IMI, the daily rate at which $\mathrm{S}$ quarters entered the herd was 0.00388 , the daily rate at which $S_{w}$ quarters entered the herd was 0.00083 , and the daily rate at which I quarters entered the herd was 0.00041. For the combined event of CNS IMI and transient colonization, the corresponding estimates for S, $\mathrm{S}_{\mathrm{w}}$, and I were 0.00271, 0.00155, and 0.00076 .

Estimates for the Basic Reproduction Number. The $R_{0}$ for the combination of transient colonization and IMI by CNS was 1.13 in farm 1 and 1.17 in farm 2 ; the $R_{0}$ for cases of CNS IMI was 0.59 in farm 1 and 0.84 in farm 2 (Table 2).
Risk of a Second CNS Event in Previous CNSPositive Quarters. The likelihood for CNS IMI was not different between the first and subsequent infection in either farm. For farm 1, RR $=0.96=\mathrm{e}^{-0.0406}(95 \% \mathrm{CI}$ : $0.53-1.72 ; P=0.89)$, and for farm $2, \mathrm{RR}=1.0=\mathrm{e}^{-0.0013}$ (95\% CI: $0.56-1.72 ; P=0.99)$.

\section{Simulations}

The proportions of $\mathrm{I}, \mathrm{S}$, and $\mathrm{S}_{\mathrm{w}}$ quarters for farm 1 are displayed in Figure 3. The proportion of I quarters decreased until it reached 0.113 after 13 mo (Table 2). The proportions of $\mathrm{S}$ and $\mathrm{S}_{\mathrm{w}}$ quarters were 0.685 and 0.202 , respectively, at 13 mo.

Figure 4 displays the proportion of $\mathrm{I}, \mathrm{S}$, and $\mathrm{S}_{\mathrm{w}}$ quarters throughout the 13-mo simulation period on farm 2 . The proportion of infectious quarters increased until it reached a prevalence of approximately 0.111 after 13 mo (Table 2). The proportions of $\mathrm{S}$ and $\mathrm{S}_{\mathrm{w}}$ quarters were 0.648 and 0.241 , respectively, at 13 mo.

The model results for $\mathrm{R}_{0}$ and $\mathrm{R}_{\mathrm{t}}$ from cases of CNS IMI from both farms are displayed in Figure 5. In farm

Table 2. Proportion of quarters harboring an $\mathrm{IMI}^{1}$ by $\mathrm{CNS}(\mathrm{I})$, basic reproduction number $\left(\mathrm{R}_{0}\right)$, and effective reproduction number $\left(\mathrm{R}_{\mathrm{t}}\right)$ for $\mathrm{CNS} \mathrm{IMI}^{2}$

\begin{tabular}{lllll}
\hline & & & \multicolumn{2}{c}{13 mo } \\
\cline { 3 - 5 } Simulation & Farm & $\mathrm{R}_{0}$ & $\mathrm{I}$ & $\mathrm{R}_{\mathrm{t}}$ \\
\hline (a) Main model & 1 & 0.59 & 0.113 & 0.66 \\
(b) $50 \%$ reduction in entry of I quarters & 2 & 0.84 & 0.111 & 0.75 \\
& 1 & 0.59 & 0.073 & 0.65 \\
(c) No entry of I quarters & 2 & 0.84 & 0.072 & 0.79 \\
(d) $50 \%$ increase in $\beta$ & 1 & 0.59 & 0.031 & 0.62 \\
& 2 & 0.84 & 0.027 & 0.82 \\
& 1 & 0.87 & 0.277 & 0.93 \\
\end{tabular}

${ }^{1}$ IMI status based on definitions of Zadoks et al. (2002).

${ }^{2}$ The simulation was conducted in ModelMaker 4 (ModelKinetix, Wallingford, UK) for the following scenarios in 2 farms: (a) main model, (b) 50\% reduction in entry of CNS IMI positive quarters, (c) no entry of CNS IMI positive quarters, or (d) transmission parameters increased by $50 \%$ compared with main model. In the main model, the following parameters were used in farm 1: Transmission parameter $(\beta)=0.00658$, cure rate $(\alpha)=$ 0.00620 , daily exit and entry of the lactation pens $(\mu)=0.00489$. The corresponding figures for farm 2 were $\beta$

$=0.01113, \alpha=0.00813$, and $\mu=0.00512$. 


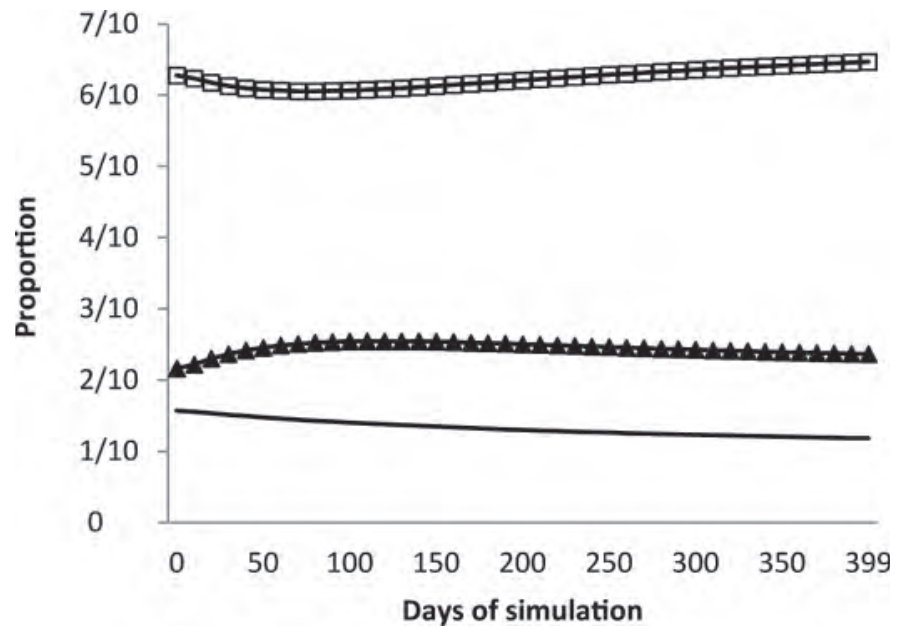

Figure 3. Proportions of naive susceptible quarters (S; $\square$ ), susceptible quarters in a cow with one or more infected quarters $\left(\mathrm{S}_{\mathrm{w}} ; \mathbf{\Lambda}\right)$ and quarters diagnosed with IMI by CNS (I; solid line) distributed by days of simulation in farm 1 . The simulation of transmission dynamics for CNS IMI was performed in ModelMaker 4 (ModelKinetix, Wallingford, UK). Transmission parameter $(\beta)=0.00658$, cure rate $(\alpha)=0.00620$, daily rate of exit and entry $(\mu)=0.00489$, increased risk of transmission between quarters within the same cow $(\sigma)=1.99$. The IMI status was based on definitions of Zadoks et al. (2002).

$1, R_{t}$ was higher than $R_{0}$ and reached 0.66 after 13 mo (Table 2). Both $R_{0}$ and $R_{t}$ were greater in farm 2 than in farm 1 . In farm $2, \mathrm{R}_{\mathrm{t}}$ was 0.74 after 13 mo (Table 2). In contrast to farm $1, \mathrm{R}_{\mathrm{t}}$ was less than $\mathrm{R}_{0}$ throughout the whole simulation period in farm 2 .

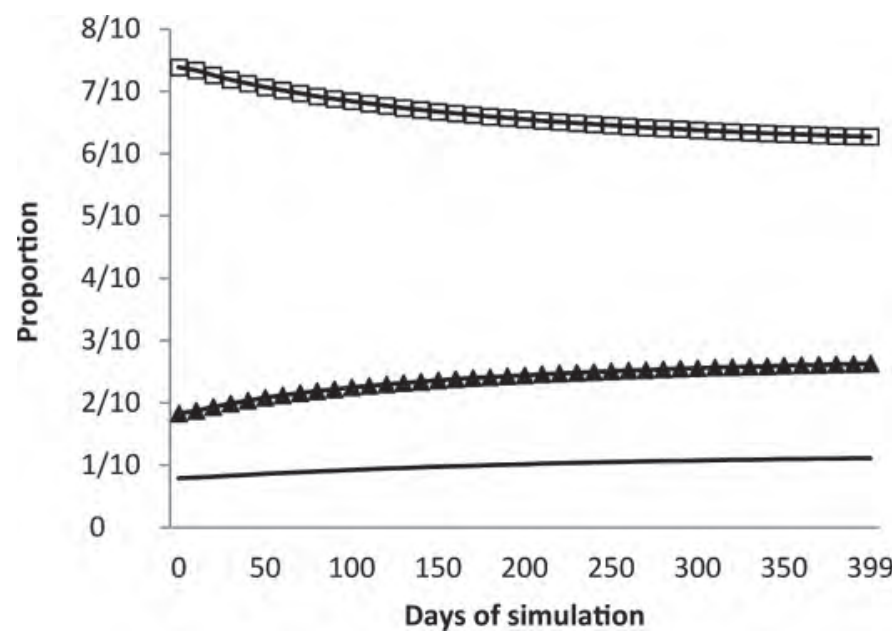

Figure 4. Proportions of naive susceptible quarters (S; $\square$ ), susceptible quarters in a cow with one or more infected quarters $\left(\mathrm{S}_{\mathrm{w}} ; \boldsymbol{\Delta}\right)$, and quarters diagnosed with IMI by CNS (I; solid line) distributed by days of simulation in farm 2 . The simulation of transmission dynamics for CNS IMI was performed in ModelMaker 4 (ModelKinetix Wallingford, UK). Transmission parameter $(\beta)=0.01113$, cure rate $(\alpha)=0.00813$, daily rate of exit and entry $(\mu)=0.00512$, increased risk of transmission between quarters within the same cow $(\sigma)=0.99$. The IMI status was based on definitions of Zadoks et al. (2002).

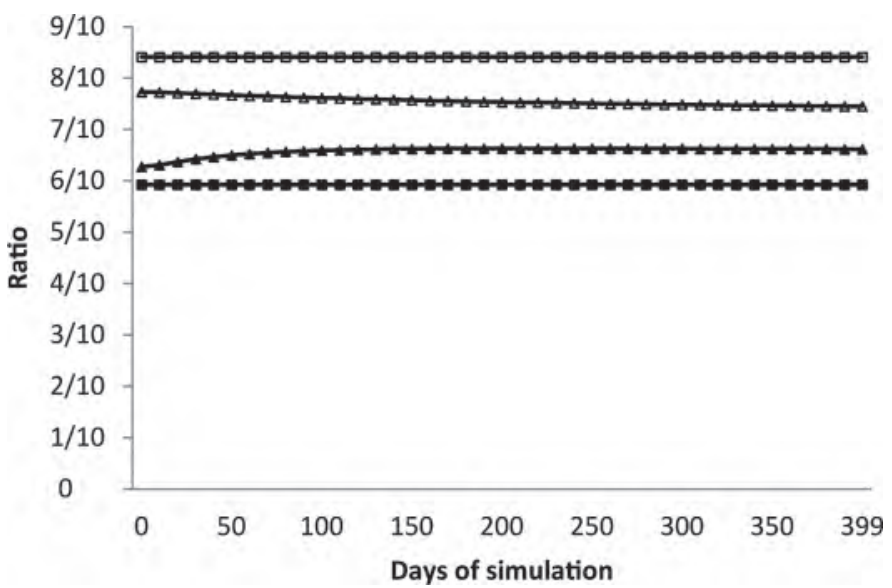

Figure 5. Simulation of basic reproduction ratio $\left(\mathrm{R}_{0}: \boldsymbol{\square}\right)$ and effective reproductive ratio $\left(\mathrm{R}_{t} ; \boldsymbol{\Delta}\right)$ for IMI with CNS in farm 1 (solid symbols) and farm 2 (open symbols) performed in ModelMaker 4 (ModelKinetix, Wallingford, UK) distributed by days of simulation. The parameters used for farm 1 were as follows: transmission parameter $(\beta)=0.00658$, cure rate $(\alpha)=0.00620$, daily rate of exit and entry $(\mu)=0.00489$, increased risk of transmission between quarters within the same cow $(\sigma)=1.99$. The corresponding parameters for farm 2 were $\beta=0.01113, \alpha=0.00813, \mu=0.00512$, and $\sigma=0.99$. The IMI status was based on definitions of Zadoks et al. (2002).

Simulations of the transmission dynamics when entry of CNS IMI affected quarters from the fresh pen into the lactation pen was (1) halved or (2) set to zero are illustrated in Figure 6 for both farms. For scenario (1) in farm 1, the proportion of infected quarters reached 0.073 after 13 mo (Table 2) and continued to decrease to reach 0.048 after a 4 -yr simulation period. In farm 2 , the proportion of infected quarters decreased to 0.072 after 13 mo (Table 2) and stabilized at 0.071 when the simulation was extended to $4 \mathrm{yr}$.

For scenario (2) in farm 1, the proportion of CNS IMI affected quarters declined rapidly and reached 0.031 after 13 mo. An almost identical decrease in the prevalence of CNS IMI was observed in farm 2 when no infectious quarters entered the pen from outside (Table 2 ). The proportion of infected quarters in this farm reached 0.027 after the 13 -mo simulation period. The prevalence approached zero in both farms when the simulation period was extended to $4 \mathrm{yr}$; the results are in accordance with the small $\mathrm{R}_{0}$ values and show that CNS from IMI was not sufficiently contagious to maintain the observed prevalence of CNS IMI only through transmission during the lactation period.

In farm 1, the proportion of infected quarters reached 0.277 after $13 \mathrm{mo}$, and $\mathrm{R}_{0}$ was 0.87 when the transmission parameter $(\beta)$ increased by $50 \%$ to 0.00986 (Table 2 ). In farm 2 , the proportion of quarters with CNS IMI reached 0.253 after $13 \mathrm{mo}$, and $\mathrm{R}_{0}$ was 1.26 when the transmission parameter $(\beta)$ increased by $50 \%$ to 0.01671 (Table 2). 


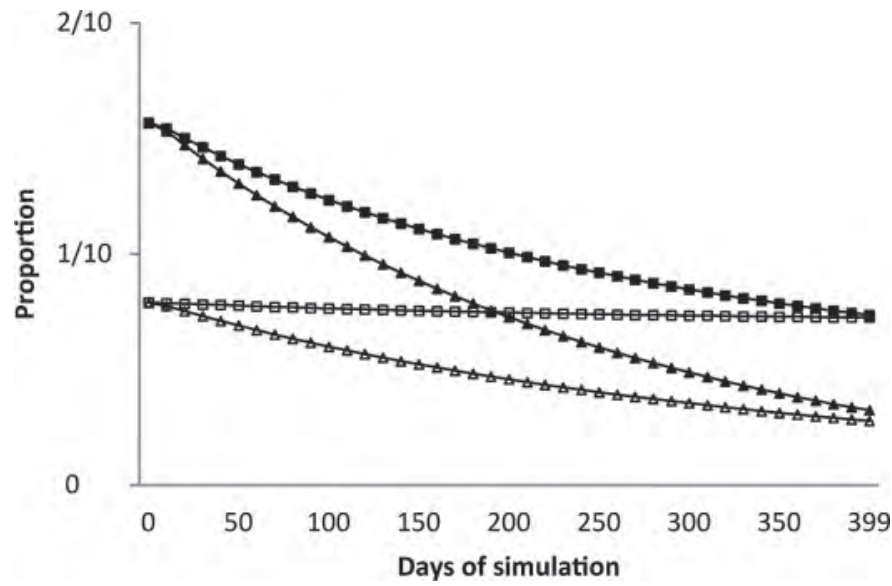

Figure 6. Two scenarios for transmission dynamics of IMI with CNS. Scenario (1): Proportion of infectious quarters affected by IMI with CNS in farm 1 (ם) and farm $2(\square)$ by days of study after reducing entry of already infected quarters to half of the true number. Scenario (2): Corresponding estimates of infectious quarters in farm 1 $(\boldsymbol{\Delta})$ and farm $2(\Delta)$ after exclusion of entry of already infected quarters into the lactation pens. The simulation was run in ModelMaker 4 (ModelKinetix, Wallingford, UK). The initial parameters used for farm 1 were as follows: Transmission parameter $(\beta)=0.00658$, cure rate $(\alpha)=0.00620$, daily rate of exit and entry $(\mu)=0.00489$, and rate of quarters with IMI entering the lactation pen per day $\left(\theta_{\mathrm{i}}\right)=$ 0.00040 . The corresponding parameters for farm 2 were $\beta=0.01113$, $\alpha=0.00813, \mu=0.00512$, and $\theta_{\mathrm{i}}=0.00041$. The IMI status was based on definitions of Zadoks et al. (2002).

\section{DISCUSSION}

The differentiation between IMI and transient colonization of CNS is not always clear, as a milk culture might test positive for a microorganism due to clinical or subclinical mastitis (Harmon, 1994) or because of transient colonization of the teat canal and teat cistern with no major involvement of the mammary parenchyma (Persson et al., 1995; Taponen et al., 2007). Some studies have defined a minimum number of colonyforming units per $\mathrm{ml}(\mathrm{cfu} / \mathrm{mL})$ to be the criterion for discrimination between IMI and transient colonization (Djabri et al., 2002; Pitkala et al., 2004; Østerås et al., 2006); others have used a combination of repeated positive diagnoses for CNS (Davidson et al., 1992; Taponen et al., 2007; Thorberg et al., 2009) or Staph. aureus (Zadoks et al., 2002) in combination with threshold values for the differentiation. We have used a combination of threshold bacterial count values for CNS and persistency in monthly milk samples to differentiate between IMI and incidental isolation events (Zadoks et al., 2002).

Because the definition of CNS IMI differs between studies, the prevalence reported in previous investigations also varies (Pitkala et al., 2004; Østerås et al., 2006). The prevalence of CNS IMI in the current study were in accordance with a meta-analysis conducted in
2002 (Djabri et al., 2002), which reported the prevalence of IMI caused by CNS to vary between 5.5 and $27.1 \%$ at quarter level. More recent investigations report figures similar to those observed in the current study (Østerås et al., 2006; Schukken et al., 2009; Thorberg et al., 2009). In accordance with most reports (Djabri et al., 2002; Pyörälä and Taponen, 2009), the majority of CNS IMI in the present investigation were not clinical, and only 4 clinical cases were recorded. Subclinical mastitis has been defined as an infection with no visible changes in the appearance of the milk or the mammary gland, although milk production decreases, bacteria are present in the secretion, and inflammatory changes in the milk can be detected by special tests such as SCC (Harmon, 1994; National Mastitis Council, 1996). Although routinely recorded, cow-level SCC is less useful for the differentiation between IMI and a transient colonization of the teat canal and cistern at the quarter level (Thorberg et al., 2009). Persistency of CNS in sequential milk samples may be a better way to characterize IMI by these microorganisms (Davidson et al., 1992; Thorberg et al., 2009).

In mastitis diagnostics, staphylococci are divided into coagulase-positive staphylococci and CNS based on their ability to coagulate rabbit plasma. The classification of staphylococci into 2 groups has traditionally been considered sufficient for diagnostic purposes in dairy cattle (Taponen and Pyörälä, 2009). In this study, CNS positive samples were not further differentiated to the species level; thus, we cannot make any epidemiological or biological observations at the species level. Except for Staph. chromogenes, CNS species isolated from the teat skin, teat apex, and teat canal have been found to be different from those species isolated from IMI (De Vliegher et al., 2003; Taponen and Pyörälä, 2009). Consequently, the current investigation focused on studying the effect of existing CNS IMI on new occurrences of CNS IMI during lactation. We acknowledge that new IMI may have occurred because of transmission from CNS isolates that were not defined as IMI in the current investigation, such as teat apex or skin isolates (De Vliegher et al., 2003). Therefore, transmission dynamics of the combination of transient colonization and IMI by CNS have also been studied. In this scenario, $\mathrm{R}_{0}$, although rather low, would theoretically be sufficient to maintain an endemic CNS infection in both herds (Keeling and Rohani, 2007).

We speculate that CNS IMI in our study were likely caused by the more common CNS species prevailing in bovine mastitis: Staph. chromogenes, Staph. simulans, and Staph. epidermidis (Matthews et al., 1992; Aarestrup et al., 1999; Thorberg et al., 2009). In accordance with previous studies (Todhunter et al., 1993; Aarestrup and Jensen, 1997; Taponen et al., 2007), the 
spontaneous cure rates were only slightly lower than $\beta$, showing that CNS IMI is likely to persist over several months. The prevalence of CNS IMI also remained relatively constant throughout the simulation, although both $\mathrm{R}_{0}$ and $\mathrm{R}_{\mathrm{t}}$ were $<1$. Contagious transmission as modeled as IMI in this paper was not able to maintain CNS infection prevalence in the herd. Other transmission mechanisms or transmission outside the lactation period is necessary to explain the observed data. The prevalence of CNS IMI events during lactation, as predicted by the simulation model, is the sum of preexisting CNS IMI, new events emerging during the lactation period, and the entry of already existing CNS-positive quarters from the fresh pen into the lactation pen. The relatively high rates of IMI entering the lactation pen after calving indicate that CNS events occurring during dry off, the dry period, and early postpartum make important contributions to the endemic situation seen in these herds.

The fact that $R_{t}$ exceeded $R_{0}$ in farm 1 is probably due to the combination of a high likelihood of quarterto-quarter transmission within the same cow and entry of infected quarters from the fresh pen. Neither of the reproduction ratios for CNS IMI $\left(\mathrm{R}_{\mathrm{t}}\right.$ or $\left.\mathrm{R}_{0}\right)$ exceeded the threshold value of 1 in this study, which would have been necessary to maintain an endemic infection throughout lactation solely based on between-quarter infection transmission (Keeling and Rohani, 2007). Because CNS apparently persisted in the population, it is necessary that CNS IMI becomes endemic partly due to a high rate of infection in the dry period, resulting in many infectious quarters entering the lactating pens after calving. This underscores the importance of preventive measures against CNS IMI not only during lactation, but also during the periods of drying off and calving. This was also demonstrated in simulations in which the entry of infected quarters to the lactating pens was halved. When entry of already infected quarters to the lactation pens was set to zero, CNS IMI would, in theory, disappear from both herds after a simulation period over $4 \mathrm{yr}$. The current study showed a lower transmissibility of CNS than reported in a previous study of minor pathogens (White et al., 2006). Therefore, we also found it realistic to simulate a scenario with a $50 \%$ increase in the transmission parameter. In these simulations, farm 2 attained values for $\mathrm{R}_{0}>1$ for CNS IMI.

To the best of our knowledge, this is the first publication of a quarter-level state-transition model of mastitis pathogen transmission that accounts for within-udder (or cow level) infection dynamics. Barkema et al. (1997) previously reported estimates for interdependence of quarters within cows for infections caused by differ- ent pathogens, including CNS. Here, we report the use of a function informed by the size of the within-cow susceptible quarters and infected quarters to represent relative differences in infection probabilities of quarters within cows with variable numbers of infected quarters. In the proposed model, it was not possible to obtain a fully accurate estimate of the proportion of quarters that come from a cow with only one quarter infected (denoted as $\mathrm{P}$ ). We estimated this proportion as $\mathrm{S}_{\mathrm{w}} / 3 \mathrm{I}$, and simulations showed that this estimate was close but slightly biased. This method is therefore not a perfect approximation but appears to be an adequate solution to the problem of modeling mastitis pathogen transmission at the quarter level while accounting for cow level effects of infection risk. Further research comparing alternative solutions and model fit to independent observed data are required.

A higher likelihood for a second CNS event was not found in quarters previously diagnosed positive for IMI by CNS in the current investigation. In contrast to indications of a protective effect of CNS against subsequent IMI (Pyörälä and Taponen, 2009), neither a predisposition to become infected by subsequent infections with CNS nor a protective effect of previous CNS IMI on a subsequent CNS IMI was apparent in our study. This indicates that farm- and CNS species-specific discussions are needed to alleviate CNS-related herd problems rather than general advice on CNS management. The CNS species causing IMI also differ in persistency from Staph. aureus, where a higher likelihood for transmission of the bacteria has been seen in quarters that have recovered from a previous infection than in a naive susceptible quarter (Zadoks et al., 2002; Barlow et al., 2009).

In accordance with the findings in our study, previous investigations of pathogens other than CNS have shown marked variability in transmission parameters between farms (White et al., 2006; Barlow et al., 2009). In farm 2 , both a lack of improvement of the model incorporating $\mathrm{I} / \mathrm{N}$ and the absence of quarter-to-quarter transmission within the same cow are indicative of differences in CNS transmission between farm 2 and farm 1 of the study. The variation in transmission parameters for CNS IMI between the 2 herds in our study may be due to variations in prevailing CNS species or herd management. Proper milking management and teat dipping are accepted as important strategies to reduce transmission of mastitis pathogens and thereby lower SCC and decrease the number of subclinical and clinical mastitis in larger high-yielding herds (Huijps et al., 2010; Dufour et al., 2011). The current investigation was not able to provide an explicit answer to this question, which will need clarification in future research. 


\section{CONCLUSIONS}

The current study presents novel approaches for mathematical modeling of CNS transmission between cows and between quarters within the same cow. The models allow for quantification of the effect of interventions. A potential for sustained endemic transmission throughout lactation was apparent when transient colonization and IMI caused by CNS were modeled jointly. However, prevailing CNS species may differ between transient colonization and IMI. Under such conditions, continuous entry of infected quarters from the fresh pen was required to maintain CNS IMI as an endemic infection in both farms studied. Different simulation scenarios showed that preventive measures against CNS IMI should emphasize the dry period and early lactation. The transmission coefficient of CNS IMI varied between herds, and quarter-to-quarter transmission within the same cow was increased in one but not both farms. Further studies including species differentiation are needed to fully explain the differences in transmission dynamics of CNS.

\section{ACKNOWLEDGMENTS}

The authors acknowledge the contribution of participating farm owners and farm staff. The support of our field and laboratory staff is also greatly appreciated. The data for this study were available due to a previous study on subclinical mastitis supported in part by funding from Pfizer Animal Health (Madison, NJ), USDA Cooperative State Research, Education, and Extension Service (CSREES, Washington, DC), National Research Initiative award \# 2005-35204-15651, USDACSREES Vermont Agricultural Experiment Station Animal Health and Disease award \# VT-AH01011, and the Multi-State Mastitis Research Project USDA CSREES NE-1028 (formerly NE-1009).

\section{REFERENCES}

Aarestrup, F. M., and N. E. Jensen. 1997. Prevalence and duration of intramammary infection in Danish heifers during the peripartum period. J. Dairy Sci. 80:307-312.

Aarestrup, F. M., H. D. Larsen, and N. E. Jensen. 1999. Characterization of Staphylococcus simulans strains isolated from cases of bovine mastitis. Vet. Microbiol. 66:165-170.

Barkema, H. W., Y. H. Schukken, T. J. Lam, D. T. Galligan, M. L. Beiboer, and A. Brand. 1997. Estimation of interdependence among quarters of the bovine udder with subclinical mastitis and implications for analysis. J. Dairy Sci. 80:1592-1599.

Barlow, J. W., L. J. White, R. N. Zadoks, and Y. H. Schukken. 2009. A mathematical model demonstrating indirect and overall effects of lactation therapy targeting subclinical mastitis in dairy herds. Prev. Vet. Med. 90:31-42.

Davidson, T. J., I. R. Dohoo, A. W. Donald, H. Hariharan, and K. Collins. 1992. A cohort study of coagulase-negative staphylococcal mastitis in selected dairy herds in Prince Edward Island. Can. J. Vet. Res. 56:275-280.

De Vliegher, S., H. Laevens, L. A. Devriese, G. Opsomer, J. L. M. Leroy, H. W. Barkema, and A. de Kruif. 2003. Prepartum teat apex colonization with Staphylococcus chromogenes in dairy heifers is associated with low somatic cell count in early lactation. Vet. Microbiol. 92:245-252.

Dingwell, R. T., K. E. Leslie, Y. H. Schukken, J. M. Sargeant, L. L. Timms, T. F. Duffield, G. P. Keefe, D. F. Kelton, K. D. Lissemore, and J. Conklin. 2004. Association of cow and quarter-level factors at drying-off with new intramammary infections during the dry period. Prev. Vet. Med. 63:75-89.

Djabri, B., N. Bareille, F. Beaudeau, H. Seegers, and H. G. Allore. 2002. Quarter milk somatic cell count in infected dairy cows: A meta-analysis. Vet. Res. 33:335-357.

Dufour, S., A. Frechette, H. W. Barkema, A. Mussell, and D. T. Scholl. 2011. Invited review: Effect of udder health management practices on herd somatic cell count. J. Dairy Sci. 94:563-579.

Harmon, R. J. 1994. Physiology of mastitis and factors affecting somatic cell counts. J. Dairy Sci. 77:2103-2112.

Hogan, J. S., R. N. González, R. J. Harmon, S. C. Nickerson, J. W. Pankey, and K. L. Smith. 1999. Laboratory Handbook on Bovine Mastitis. National Mastitis Council, Madison, WI.

Huijps, K., H. Hogeveen, T. J. G. M. Lam, and A. G. J. M. Oude Lansink. 2010. Costs and efficacy of management measures to improve udder health on Dutch dairy farms. J. Dairy Sci. 93:115-124.

International Dairy Federation. 1987. Bovine Mastitis: Definition and Guidelines for Diagnosis. Int. Dairy Fed., Brussels, Belgium.

Keeling, M. J., and P. Rohani. 2007. Modeling Infectious Diseases in Humans and Animals. Princeton University Press, Princeton, NJ.

Matthews, K. R., R. J. Harmon, and B. E. Langlois. 1992. Prevalence of Staphylococcus species during the periparturient period in primiparous and multiparous cows. J. Dairy Sci. 75:1835-1839.

National Mastitis Council. 1996. Current Concepts of Bovine Mastitis. Natl. Mastitis Counc., Madison, WI.

Østerås, O., L. Sølverød, and O. Reksen. 2006. Milk culture results in a large Norwegian survey-Effects of season, parity, days in milk, resistance, and clustering. J. Dairy Sci. 89:1010-1023.

Persson, K., B. Amolina, and P. Jonsson. 1995. Inflammation in the bovine teat cistern induced by Staphylococcus aureus. Zentralbl. Vet. Med. B 42:435-442.

Pitkälä, A., M. Haveri, S. Pyörälä, V. Myllys, and T. Honkanen-Buzalski. 2004. Bovine mastitis in Finland 2001-Prevalence, distribution of bacteria, and antimicrobial resistance. J. Dairy Sci. $87: 2433-2441$

Pyörälä, S., and S. Taponen. 2009. Coagulase-negative staphylococciEmerging mastitis pathogens. Vet. Microbiol. 134:3-8.

Reksen, O., L. Sølverød, A. J. Branscum, and O. Østerås. 2006. Relationships between milk culture results and treatment for clinical mastitis or culling in Norwegian dairy cattle. J. Dairy Sci. 89:2928-2937.

Reksen, O., L. Sølverød, and O. Østerås. 2008. Relationships between milk culture results and composite milk somatic cell counts in Norwegian dairy cattle. J. Dairy Sci. 91:3102-3113.

Safan, M., H. Heesterbeek, and K. Dietz. 2006. The minimum effort required to eradicate infections in models with backward bifurcation. J. Math. Biol. 53:703-718.

Schukken, Y. H., R. N. González, L. L. Tikofsky, H. F. Schulte, C. G. Santisteban, F. L. Welcome, G. J. Bennett, M. J. Zurakowski, and R. N. Zadoks. 2009. CNS mastitis: Nothing to worry about? Vet. Microbiol. 134:9-14.

Supré, K., F. Haesebrouck, R. N. Zadoks, M. Vaneechoutte, S. Piepers, and S. De Vliegher. 2011. Some coagulase-negative Staphylococcus species affect udder health more than others. J. Dairy Sci. 94:2329-2340.

Taponen, S., J. Koort, J. Bjorkroth, H. Saloniemi, and S. Pyörälä. 2007. Bovine intramammary infections caused by coagulase-negative staphylococci may persist throughout lactation according to amplified fragment length polymorphism-based analysis. J. Dairy Sci. 90:3301-3307. 
Taponen, S., and S. Pyörälä. 2009. Coagulase-negative staphylococci as cause of bovine mastitis - Not so different from Staphylococcus aureus? Vet. Microbiol. 134:29-36.

Taponen, S., H. Simojoki, M. Haveri, H. D. Larsen, and S. Pyörälä 2006. Clinical characteristics and persistence of bovine mastitis caused by different species of coagulase-negative staphylococci identified with API or AFLP. Vet. Microbiol. 115:199-207.

Thorberg, B. M., M. L. Danielsson-Tham, U. Emanuelson, and K. Persson Waller. 2009. Bovine subclinical mastitis caused by different types of coagulase-negative staphylococci. J. Dairy Sci 92:4962-4970

Todhunter, D. A., L. L. Cantwell, K. L. Smith, K. H. Hoblet, and J. S. Hogan. 1993. Characteristics of coagulase-negative staphylococci isolated from bovine intramammary infections. Vet. Microbiol. $34: 373-380$.
Waage, S., T. Mørk, A. Røros, D. Aasland, A. Hunshamar, and S. A Ødegaard. 1999. Bacteria associated with clinical mastitis in dairy heifers. J. Dairy Sci. 82:712-719.

White, L. J., T. J. G. M. Lam, Y. H. Schukken, L. E. Green, G. F Medley, and M. J. Chappell. 2006. The transmission and control of mastitis in dairy cows: A theoretical approach. Prev. Vet. Med. 74:67-83.

White, L. J., Y. H. Schukken, B. Dogan, L. Green, D. Dopfer, M. J. Chappell, and G. F. Medley. 2010. Modelling the dynamics of intramammary E. coli infections in dairy cows: Understanding mechanisms that distinguish transient from persistent infections. Vet. Res. 41:13.

Zadoks, R. N., H. G. Allore, T. J. Hagenaars, H. W. Barkema, and Y. H. Schukken. 2002. A mathematical model of Staphylococcus aureus control in dairy herds. Epidemiol. Infect. 129:397-416. 